\title{
Effects of 5-Fluorouracil and Pantoyl Lactone on Viability and Division of Ultraviolet-irradiated Escherichia coli $\mathrm{FIL}^{+}$and $\mathrm{FIL}^{-}$
}

\author{
By P. A. SWENSON, R. L. SCHENLEY AND J. M. BOYLE \\ Biology Division, Oak Ridge National Laboratory, Oak Ridge, \\ Tennessee, 37830, U.S.A. and \\ Paterson Laboratories, Christie Hospital and Holt Radium \\ Institute, Manchester, M20 9Bx
}

(Accepted for publication 7 March 1972)

SUMMARY

Escherichia coli strains B Hill(FIL $\left.{ }^{+}\right)$and $\mathrm{B} / \mathrm{r}\left(\mathrm{FIL}^{-}\right)$, when grown on minimal medium containing glycerol, ceased respiration for several hours after ultraviolet (u.v.) irradiation at $520 \mathrm{ergs} / \mathrm{mm}^{2}$. Treatment of cells with 5 -fluorouracil (FU) had two effects on viability: (i) pre-irradiation treatment enhanced survival of $E$. coli в Hill(FIL $\left.{ }^{+}\right)$but not that of $\mathrm{B} / \mathrm{r}\left(\mathrm{FIL}^{-}\right)$when survival was measured immediately after irradiation; (ii) pre- or postirradiation treatment of either strain resulted in a large and rapid increase in viability over the first hour of postirradiation incubation. Postirradiation treatment with pantoyl lactone (PL) resulted in a moderate increase in viability, but maintenance of growth and respiration was favoured only by FU. Postirradiation treatment with FU and PL together produced kinetics of respiration, growth and viability intermediate between those observed when the drugs were used separately. Irradiated в Hill organisms, which usually form filaments after u.v. irradiation, only did so in glycerol medium when FU was present. If FU was then replaced by PL, the filaments broke up and viability increased. Viability of в Hill was always higher when irradiated bacteria were plated on agar containing PL than without PL. Thus the increased viability caused by PL and FU when present singly during postirradiation incubation occurred by different means: PL by stimulation of division, and FU by maintenance of respiration.

\section{INTRODUCTION}

Ultraviolet (u.v.) irradiation of Escherichia coli $\mathrm{B} / \mathrm{r}$ grown on minimal medium containing glycerol as the sole source of carbon causes respiration to cease for several hours, beginning about I h after irradiation (Swenson \& Schenley, 1970a). The cessation of respiration requires transcription and translation of the irradiated DNA and is associated with a loss of pyridine nucleotides (Swenson \& Schenley, 1970 $b$ ). Postirradiation treatment of u.v.irradiated cells with agents that interfere with these processes results in continued respiration and the maintenance of high levels of pyridine nucleotides. 5-Fluorouracil (FU), used extensively by us (Boyle, Schenley \& Swenson, I97I) to study this effect, presumably acts causing coding errors in mRNA. In FU-treated organisms a large increase in viability, which cannot be explained on the basis of division, occurs during the first hour of postirradiation incubation.

Ben-Ishai and co-workers treated Escherichia coli with FU before u.v. exposure and assayed their survival immediately thereafter (Ben-Ishai, Goldin \& Oppenheim, 1962; Ben-Ishai, Cavari, Goldin \& Kerpel, 1965). They found no pretreatment effect with strain $\mathrm{B} / \mathrm{r}$ (a FIL- strain) but did find an increase in viability with FIL $^{+}$strains (Ben-Ishai \& 
Zeevi, 1967). Such strains (e.g. B Hill) form long filaments after low doses of u.v. or ionizing radiation under some conditions (van de Putte, Westenbroek \& Rorsch, I963; HowardFlanders, Simson \& Theriot, I964; Adler \& Hardigree, 1965). Ben-Ishai \& Zeevi (1967) have suggested that FU pretreatment confers u.v. resistance on $\mathrm{FIL}^{+}$bacteria by inhibiting growth and that during the period of inhibition a factor accumulates that is necessary to induce cross-wall synthesis.

We have now carried out a comparative study on the effects of pre- and postirradiation treatment with $\mathrm{FU}$ on the respiration, growth, and viability of strains $\mathrm{B} / \mathrm{r}$ and $\mathrm{B}$ Hill. We have also tested the action of pantoyl lactone (PL) on these effects. This agent in the plating medium increases the viability of u.v. irradiated $\mathrm{FIL}^{+}$but not $\mathrm{FIL}^{-}$bacteria, presumably by stimulation of division of filaments (van de Putte et al. 1963).

\section{METHODS}

Bacteria. Escherichia coli strains в Hill and $\mathrm{B} / \mathrm{r}$ (ORNL) are $\mathrm{FIL}^{+}$and $\mathrm{FIL}^{-}$, respectively. Growth and irradiation. The growth condition in minimal salts medium containing glycerol (M63gly) and the irradiation procedures have been described (Swenson \& Schenley, I $970 a, b$ ). Cultures were grown to $2 \times 10^{8}$ bacteria $/ \mathrm{ml}$, diluted $2 \cdot 5$-fold in M63gly for irradiation $\left(520 \mathrm{erg} / \mathrm{mm}^{2}\right.$ exposure at $\left.254 \mathrm{~nm}\right)$ and concentrated back to $2 \times 10^{8}$ bacteria $/ \mathrm{ml}$ for all experiments.

Treatment with FU and PL. For pretreatment with FU, log-phase bacteria $\left(2 \times 10^{8} / \mathrm{ml}\right)$ were incubated at $37^{\circ} \mathrm{C}$ in M63gly with FU (final concentration $0.5 \mu \mathrm{g} / \mathrm{ml}$ ) for $20 \mathrm{~min}$. Pretreatment for this period of time produced the maximum effect on viability. At the end of the incubation period the bacteria were washed and resuspended in M63gly at $2 \times 10^{8} / \mathrm{ml}$. For post-treatment, FU $(0.5 \mu \mathrm{g} / \mathrm{ml})$ and $\mathrm{PL}(0 . \mathrm{I} 2 \mathrm{M})$ were added as required to irradiated suspensions in M63gly. Unless otherwise specified, these chemicals were present throughout the $5 \mathrm{~h}$ incubation period.

Respiration. Oxygen consumption of $2 \mathrm{ml}$ vol. of suspension was measured at $37^{\circ} \mathrm{C}$ with a Gilson differential respirometer.

Growth. Turbidity of suspensions was measured as extinction at $600 \mathrm{~nm}$.

Viability. Cultures were suitably diluted in $\mathrm{IO}^{-3} \mathrm{M}$-phosphate buffer $\mathrm{pH} 7.0+0.0 \mathrm{I} \%$ gelatin and spread on Difco Bacto agar plates containing M63gly or M63gly plus PL (O.I2 M) (designated M63gly PL). The plates were incubated at $37{ }^{\circ} \mathrm{C}$, and colonies were counted after 2 days.

Photomicrography. The bacteria were observed using the phase optics of a Zeiss binocular research microscope (magnification $600 \times$ ), and photographs were made with a Zeiss Ikon camera with Plus X film.

Chemicals. 5-Fluorouracil was obtained from Calbiochem and DL-pantoyl lactone (2,4-dihydroxy-3,3'-dimethylbutyric acid- $\gamma$-lactone) from Sigma Chemical Co.

\section{RESULTS}

\section{Postirradiation incubation with FU and PL}

In both Escherichia coli $\mathrm{B} / \mathrm{r}$ and в Hill a dose of $520 \mathrm{erg} / \mathrm{mm}^{2}$ brought respiration to a stop about $60 \mathrm{~min}$ after u.v. irradiation (Fig. I $a, b$ ). FU allowed respiration to continue; PL did not. The effects on growth were much like those for respiration (Fig. I $c, d$ ). FU or PL caused only a slight decrease in the respiration and growth of non-irradiated bacteria. 

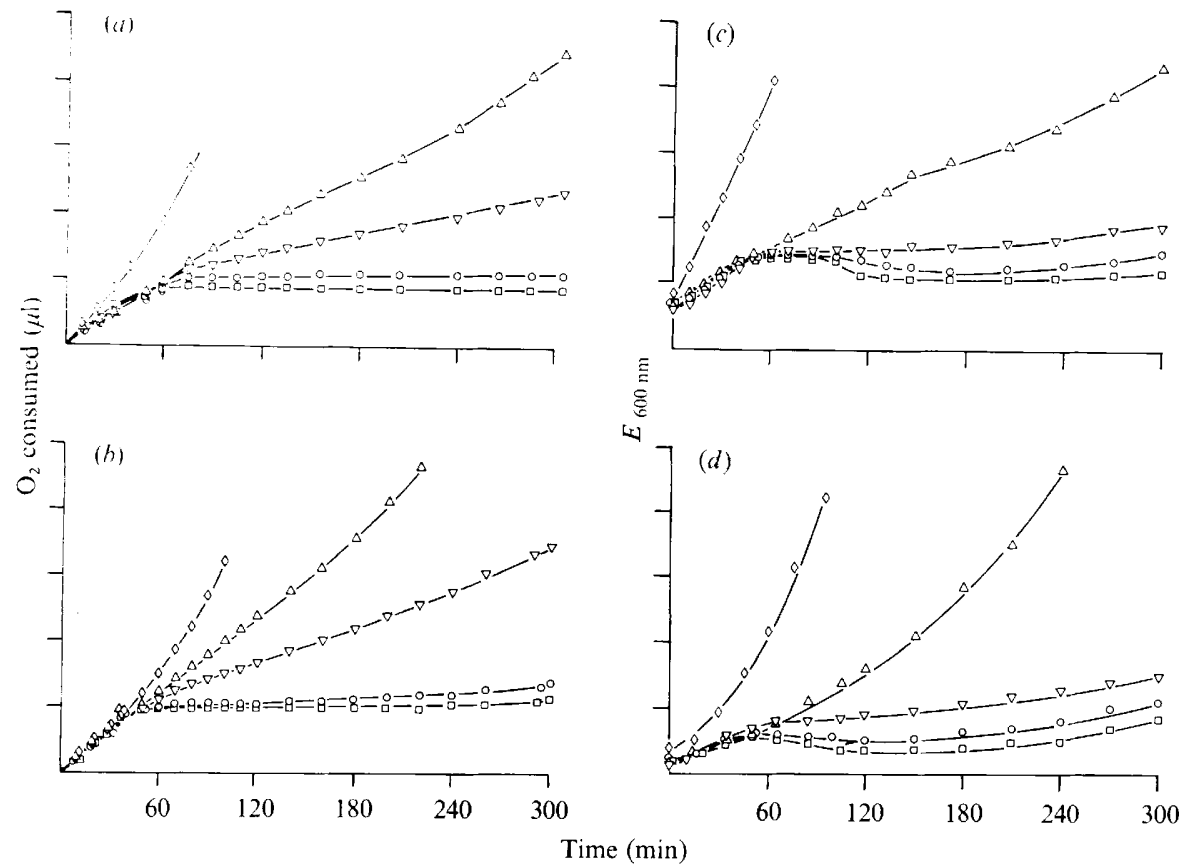

Fig. I. Effects of FU and PL on respiration and growth of u.v.-irradiated Escherichia coli $\mathbf{B} / \mathbf{r}$ and $\mathrm{B}$ Hill. (a) Respiration, B/r; (b) respiration, B Hill; (c) growth, B/r; (d) growth, B Hill. The u.v exposure was $520 \mathrm{ergs} / \mathrm{mm}^{2}$, and the chemicals were added after irradiation was completed. $\diamond$, Culture not irradiated; no chemicals added. $\square$, Irradiated; no chemicals added. $\bigcirc$, Irradiated; 0. 12 M-PL added. $\triangle$, Irradiated; $0.5 \mu \mathrm{g} / \mathrm{ml}$ FU added. $\nabla$, Irradiated; $0.12 \mathrm{M}-\mathrm{PL}$ and $0.5 \mu \mathrm{g} / \mathrm{ml}$ FU added.

Fig. 2(a,b) shows viable counts of irradiated cultures of $\mathrm{B} / \mathrm{r}$ and в Hill incubated under the same conditions as for Fig. I and plated on M63gly. FU caused a large early increase (within $60 \mathrm{~min}$ ) in viability and PL caused a moderate early increase.

\section{Interaction between $F U$ and $P L$}

Irradiated bacteria were treated with FU + PL together or sequentially with FU followed by PL. In the sequential treatment, bacteria were exposed to PL either in the plating agar or in M63gly liquid medium. PL antagonized the action of FU (Fig. I, 2). When FU and PL were added together immediately after irradiation, kinetics of respiration, growth, and viability were intermediate between those observed when the compounds were used singly.

To see whether the antagonism between FU and PL resulted from interference by PL with the entry of FU into the cell or with its incorporation into RNA, we measured the uptake of $\left[{ }^{14} \mathrm{C}\right] \mathrm{FU}$ (by its disappearance from the suspending medium) and its incorporation into RNA (i.e. into acid-insoluble material), using unirradiated and irradiated cultures of both strains. When PL was added at the same time as the $\left[{ }^{14} \mathrm{C}\right] \mathrm{FU}$, both processes were inhibited by 80 to $95 \%$ during $\mathrm{I}$ h. On the other hand, PL had little effect (less than $10 \%$

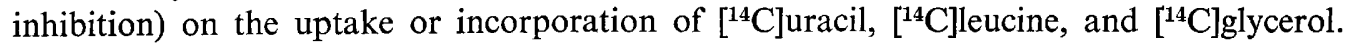
Thus the antagonism between FU and PL appears to be due to a selective action by PL on the uptake of FU.

A comparison of Fig. 2(a,b) with Fig. 2(c,d) shows that when bacteria were plated immediately after irradiation, increased survival of $\mathrm{FIL}^{+}$bacteria, but not FIL-, was obtained on plates containing PL. This result is similar to that obtained by other workers. 

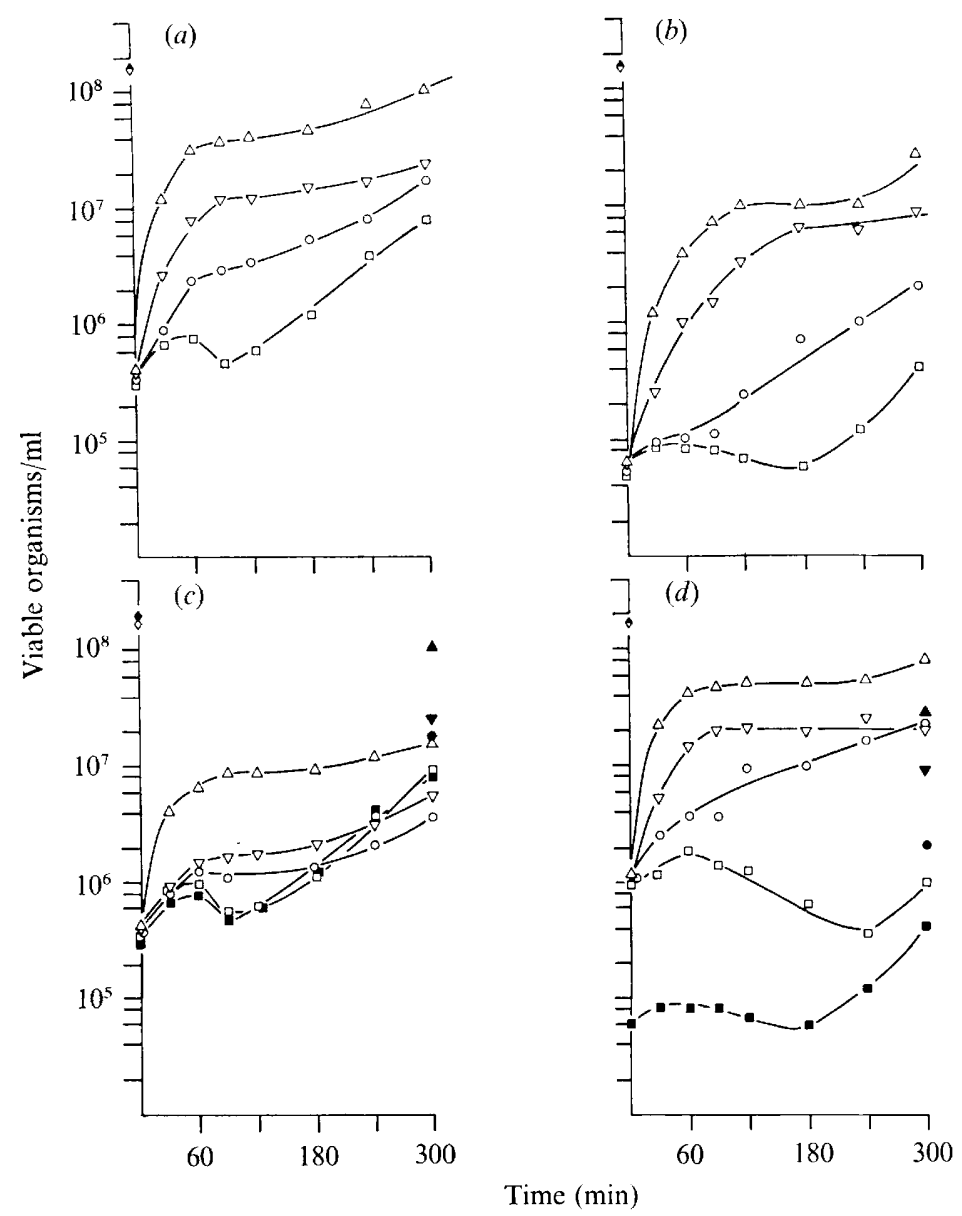

Fig. 2. Effects of FU and PL on viability of u.v.-irradiated Escherichia coli $\mathrm{B} / \mathrm{r}$ and в Hill plated on M63gly or M63glyPL agar. (a) B/r on M63gly; (b) в Hill on M63gly; (c) B/r on M63glyPL; (d) в Hill on M63glyPL. Open symbols and treatment of cultures as for Fig. I. In panels $(c)$ and $(d)$ the closed symbols refer to the data from panels $(a)$ and $(b)$ respectively.

Removal of FU from the incubation medium 20 or 150 min after its addition resulted in viability curves (Fig. 3 C, D) that were parallel to, but below, those obtained when FU was present continuously (Fig. 3B). When PL was added to bacteria from which FU had been removed (Fig. $3 \mathrm{E}, \mathrm{F}$ ), viability increases were arrested in $\mathrm{B} / \mathrm{r}$ cultures but were enhanced in B Hill cultures.

\section{Effects of $F U$ and $P L$ on filament formation}

Since PL stimulated division of filaments in u.v.-irradiated $\mathrm{FIL}^{+}$bacteria, the part that filament formation played in the survival responses was studied. Filaments were not formed by irradiated B Hill incubated in M63gly for $300 \mathrm{~min}$. When respiration and growth were allowed to occur by adding FU, filaments were formed. PL, which did not stimulate respiration, did not favour filament formation. Incubation with both FU and PL, or with FU for 150 min followed by washing and incubation with PL, eliminated most FU-induced filaments. PL also eliminated the filaments produced by incubation in nutrient medium: 


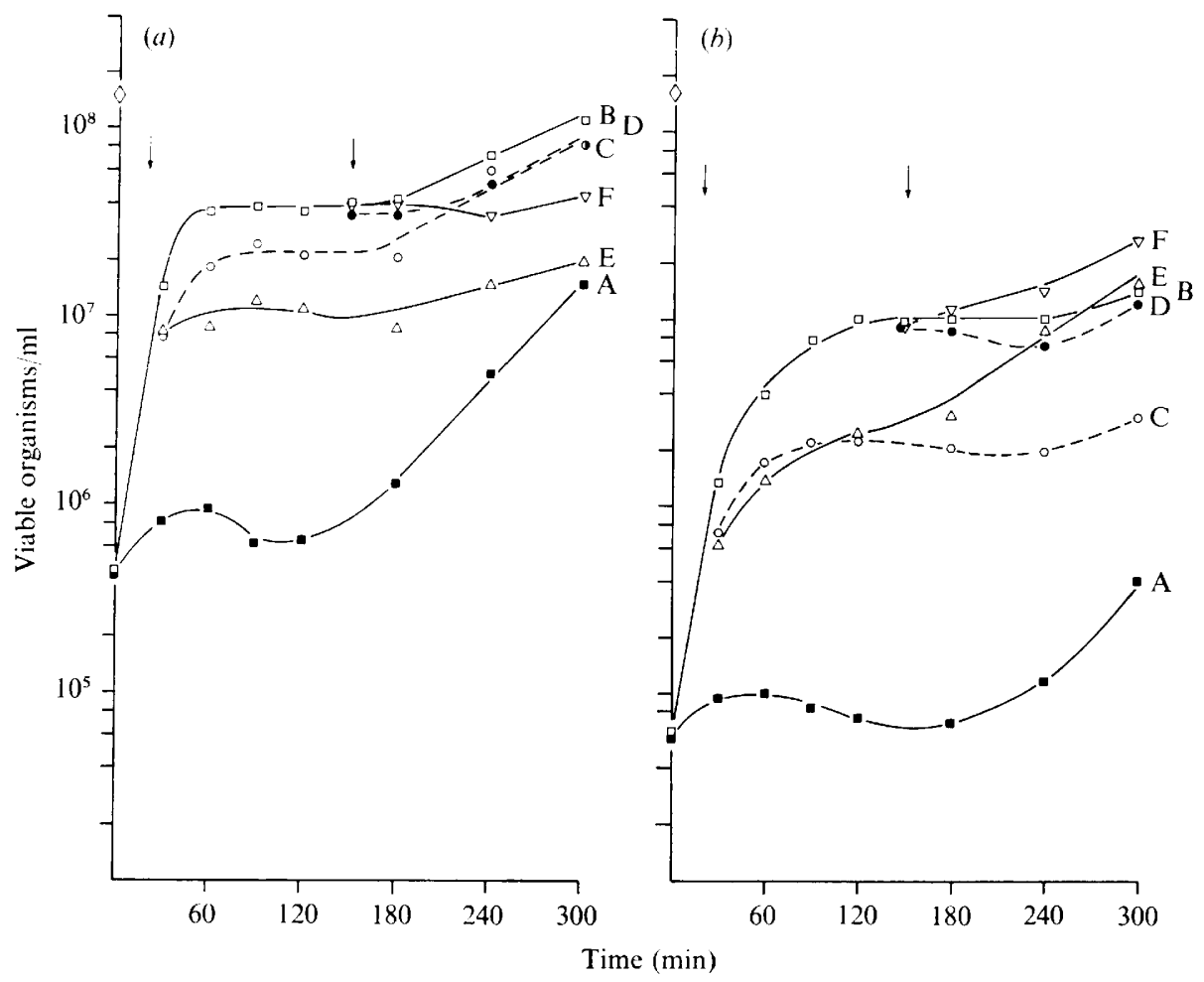

Fig. 3. Postirradiation treatment with FU and PL sequentially. Bacteria irradiated with 520 ergs/ $\mathrm{mm}^{2}$ were incubated with $0.5 \mu \mathrm{g} / \mathrm{ml} \mathrm{FU}$ for 20 or $150 \mathrm{~min}$, washed, and resuspended in M63gly or M63glyPL for further incubation. Viability assays were made on M63gly agar. Arrows indicate removal of FU. (a) B/r; (b) в Hill. $\diamond$, Non irradiated; no chemicals added. $\mathbf{\square}$, Irradiated; no chemicals added. $\square$, Irradiated; FU present continuously. $O$,, Irradiated; FU removed at 20 or I 50 min respectively. $\triangle, \nabla$, Irradiated; PL added after removal of FU at 20 or I 50 min respectively.

septa were formed and the filaments divided. None of the conditions we used produced filaments in strain $\mathrm{B} / \mathrm{r}$.

\section{Effects of pre-irradiation incubation with $F U$}

Pretreatment of bacteria with FU followed by postirradiation incubation in its absence resulted in an increase in viability which was less than that observed with postirradiation FU treatment (Figs, $4 c, 5 c$ ). As with post-treatment, the increased viability after pretreatment with FU was associated with maintenance of respiration and growth (Figs. $4 a, b$ and $5 a, b)$. Microscopic examination of irradiated bacteria following pretreatment with FU showed the formation of filaments in B Hill cultures similar to that observed with posttreatment.

It seemed likely that FU accumulated in bacteria during pretreatment was being incorporated into those species of $\mathrm{mRNA}$ which we postulate to be involved in stopping respiration following irradiation. If this were true, an excess of uracil added to the incubation medium immediately after u.v. exposure should swamp out the FU and nullify its effects. Fig. 4 and 5 demonstrate that this did occur. Uracil alone did not affect the normal respiration, growth and viability responses of irradiated organisms (Fig. 4, 5). 

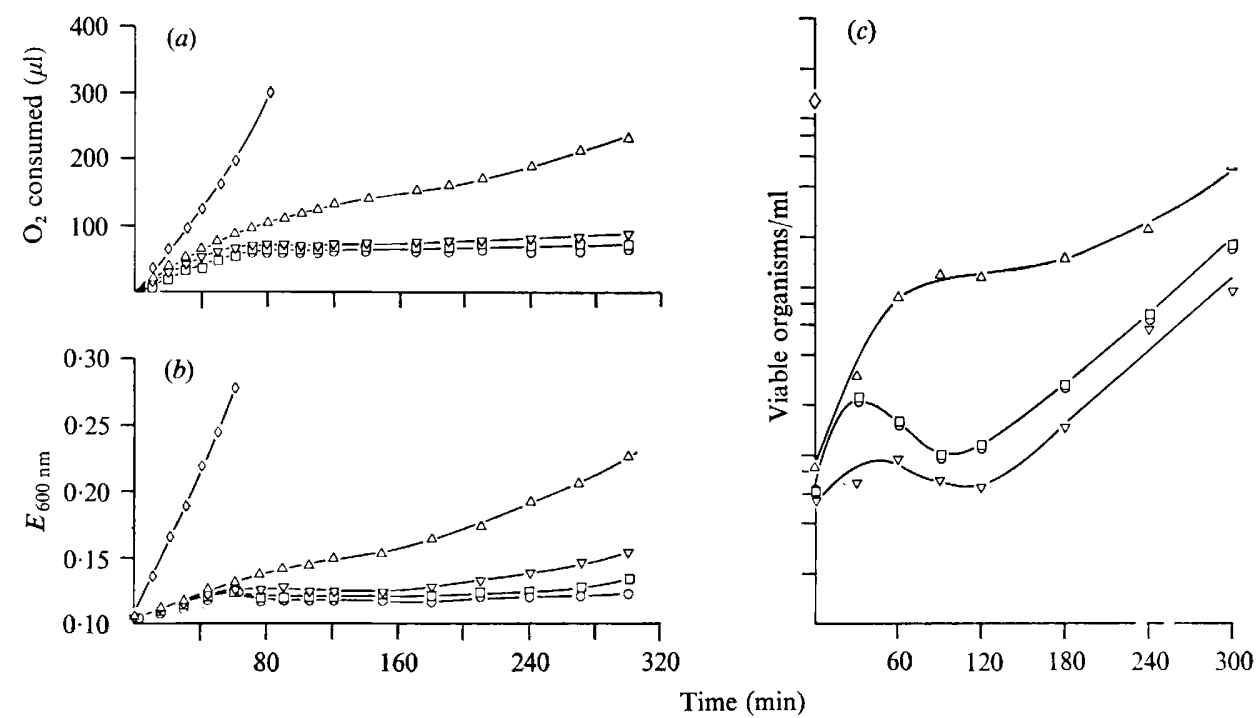

Fig. 4. Effects of adding excess uracil to irradiated $\mathrm{B} / \mathrm{r}$ bacteria that were first pretreated with FU. (a) Respiration; (b) growth; (c) viability. Cultures were pretreated with FU as described in Methods. After irradiation with $520 \mathrm{ergs} / \mathrm{mm}^{2}, 0.5 \mathrm{mg} / \mathrm{ml}$ uracil was added to the indicated cultures. $\diamond$, Nonirradiated; no FU or uracil. $\square$, Irradiated; no FU or uracil. O, Irradiated; no FU; uracil added after irradiation. $\triangle$, FU pretreated only; no uracil. $\nabla, F U$ pretreated; uracil added after irradiation.
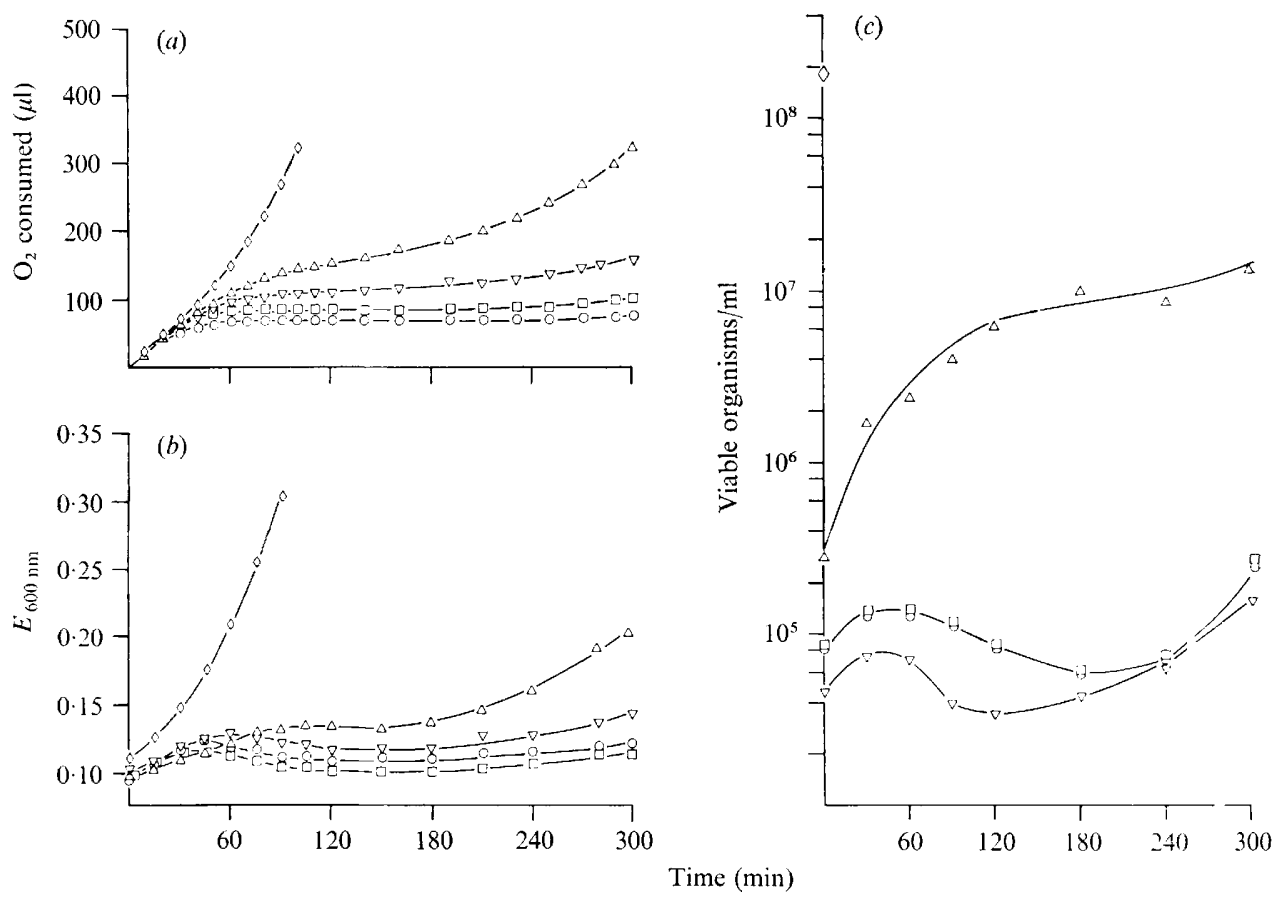

Fig. 5. Effects of adding excess uracil to irradiated в Hill bacteria pretreated with FU. (a) Respiration; (b) growth; (c) viability. Conditions as for Fig. 4. 


\section{DISCUSSION}

The experiments reported in this paper make it quite clear that FU has two effects on u.v.-irradiated bacteria. The first is obtained by pretreatment and results in increased

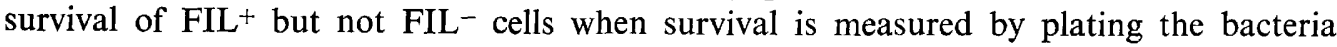
immediately after irradiation. This is the effect described by Ben-Ishai \& Zeevi (I967), who suggest that FU causes a postirradiation growth delay which allows time for accumulation of a cytokinetic factor to levels that permit the induction in $\mathrm{FIL}^{+}$cells of cross-wall synthesis before death occurs. The second is independent of the FIL phenotype and is observed when $\mathrm{FU}$ is present during postirradiation incubation.

Whether bacteria are treated with FU before or after irradiation, the postirradiation viability increases are accompanied by continued respiration and growth. We favour the idea that the two effects have a common cause - the incorporation of FU into those species of mRNA that, except for their fraudulent character, would cause the cessation of respiration. None of the pretreatment effects are observed if uracil is added immediately after irradiation to swamp out the FU. The smaller magnitude of the effects of pretreatment compared to those of post-treatment may be explained by the lower concentration of FU available for incorporation into the postulated mRNA species during the critical first hour after irradiation.

All of the effects observed during postirradiation incubation appear to be independent of the FIL phenotype, with the exception of viability and filament formation. The viability levels of irradiated FIL + bacteria were generally lower than those of FIL- bacteria throughout the $5 \mathrm{~h}$ period, and filaments were observed in irradiated $\mathrm{FIL}^{+}$cultures treated with FU. Since this condition was the only one that allowed continuous respiration and growth after u.v. treatment, it seems likely that the frequent observation that $\mathrm{FIL}^{+}$bacteria are less filamentous when grown on minimal media than on nutrient media (Adler \& Hardigree, 1965) reflects an inhibition of respiration similar to that observed with M63gly in the absence of FU. Because the early viability changes caused by FU during postirradiation incubation are similar in $\mathrm{B}$ Hill and $\mathrm{B} / \mathrm{r}$, and because $\mathrm{B}$ Hill forms filaments in M63gly medium only when FU is present, we feel that filament formation under these particular conditions has little to do with radiation sensitivity. Our observations support the interpretation that the $f$ il locus is a regulator locus that controls radiation sensitivity and capsular polysaccharide synthesis (Markovitz \& Baker, 1967).

In contrast to FU, PL does not prevent the cessation of respiration and growth, and when used together with FU, it inhibits the effect of FU on these functions, suggesting that different mechanisms cause the increased viability observed following treatment of irradiated cells with PL or FU. The action of PL is generally considered to be stimulation of septum formation, which permits bacteria that have completed DNA repair to divide and form colonies (van de Putte et al. 1963; Adler \& Hardegree, I965). In a previous paper we concluded that the increased viability of $\mathrm{B} / \mathrm{r}$ observed with postirradiation incubation with $\mathrm{FU}$ results from the maintenance of respiration (Boyle et al. 197I). High levels of pyridine nucleotides ensure that energy is available for the completion of repair processes and maintenance of respiration. One of these respiratory coenzymes, NAD, is also the coenzyme of polynucleotide ligase, the enzyme thought to be responsible for the completion of DNA repair. In the absence of FU, NAD is lost, and DNA strand breaks produced by early steps in the excision of DNA photoproducts are likely to remain and be accessible to nonspecific nuclease attack for long periods. In light of the experiments reported in this paper, the same argument can be applied to the postirradiation effect of FU on FIL ${ }^{+}$cells. 
This research was sponsored by the U.S. Atomic Energy Commission under contract with the Union Carbide Corporation.

\section{REFERENCES}

AdLER, H. I. \& HARDIGREE, A. (1965). Postirradiation growth, division and recovery in bacteria. Radiation Research 25, 92-102.

Ben Ishai, R., CAVARI, B. Z., Goldin, H. \& KerPeL, S. (I965). On the mechanism of 5-fluorouracil-induced resistance to ultraviolet irradiation in Escherichia coli. Biochimica et biophysica acta 95, 29I-30I.

Ben IsHAI, R., Goldin, H. \& OPPENHEIM, B. (1962). The effect of ultraviolet irradiation on 5-fluorouracilpretreated bacteria. Biochimica et biophysica acta 55, 748-754.

BeN IsHAI, R. \& ZeEvI, N. (1967). Postirradiation cell division in 5-fluorouracil-pretreated Escherichia coli. Journal of Bacteriology 93, 749-753.

Boyle, J. M., Schenley, R. L. \& Swenson, P. A. (1971). Role of pyridine nucleotides in 5-fluorouracilmediated reactivation of ultraviolet radiation damage. Journal of Bacteriology ro6, 896-903.

Howard-Flanders, P., Simson, E. \& ThERIOT, L. (1964). A locus that controls filament formation and sensitivity to radiation in Escherichia coli K-I2. Genetics 49, 237-246.

MARKovitz, A. \& BAKER, B. (1967). Suppression of radiation sensitivity and capsular polysaccharide synthesis in Escherichia coli K-I2 by ochre suppressors. Journal of Bacteriology 94, 388-395.

VAN DE PUTte, P., Westendroek, C. \& RoRSCH, A. (1963). The relationship between gene controlled radiation resistance and filament formation in Escherichia coli. Biochimica et biophysica acta 76, 247-256.

SWENSON, P. A. \& SCHENLEY, R. L. (1970a). Evidence for the control of respiration by DNA in ultravioletirradiated Escherichia coli $\mathrm{B} / \mathrm{r}$ cells. Mutation Research 9, 443-453.

Swenson, P. A. \& Schenley, R. L. (1970 b). Role of pyridine nucleotides in the control of respiration in ultraviolet-irradiated Escherichia coli $\mathrm{B} / \mathrm{r}$ cells. Journal of Bacteriology ro4, I230-I 235. 